\title{
Affordability of Antipsychotic Medications of Respondents who are being managed for Schizophrenia in Benin City, Nigeria
}

\author{
Joshua W Edefo $^{1 *}$, Stella F Usifoh ${ }^{2}$, Anthony W Udezi ${ }^{2}$, Jacob Egharevba ${ }^{3}$ \\ ${ }^{\mathrm{T}}$ Department of Pharmacy, Federal NeuroPsychiatric Hospital, P.M.B 1108, Benin City, Nigeria \\ ${ }^{2}$ Department of Clinical Pharmacy and Pharmacy Practice, University of Benin, P.M.B 1154, Benin City, Nigeria \\ ${ }^{3}$ Department of Pharmacy, University of Benin Teaching Hospital, P.M.B 1111, Benin City, Nigeria
}

\section{*Corresponding Author}

Joshua W Edefo

\author{
Article History \\ Received: 14.10 .2020 \\ Accepted: 31.10 .2020 \\ Published: 09.11.2020
}

\begin{abstract}
Introduction: The consequences of expensive antipsychotics medication can be two-folds. One, patients can become more impoverished due to the spending of limited financial resources on the procurement of antipsychotics. Second, the high cost of antipsychotics may be discouraging and therefore lead to poor adherence and therapeutic failure. The objective was to determine the levels of impoverishment, catastrophic expenditure and the number of days the least paid government worker will have to work due to out-of-pocket (OOP) payments of antipsychotics in a sample of patients receiving treatment for schizophrenia in Benin City. Method: A community-based cross-sectional survey among respondents who are being managed for schizophrenia was conducted using two-stage cluster sampling procedure. Outcome measures were poverty headcount ratio, poverty gap index, catastrophic expenditure and the number of days the least paid government worker will have to work to procure antipsychotics. Results: Patients with schizophrenia receiving olanzapine, risperidone, haloperidol, trifluoperazine or chlorpromazine medication are being further impoverished by $11.1 \%, 7.4 \%, 3.7 \%, 3.7 \%$ and $1.9 \%$ respectively, at the risk of catastrophic expenses by $70 \%, 64 \%, 28 \%, 28 \%, 34 \%$ respectively while that of number of days the least paid government worker will have to work to get their drugs were 1.8 day, 1.35 day, 0.15 day, 0.15 day, 0.21 day respectively. Conclusion: Antipsychotics such as olanzapine and risperidone are far less affordable than chlorpromazine, haloperidol and trifluoperazine.
\end{abstract}

Keywords: Affordability, Antipsychotics, Pharmacoeconomics, Catastrophic, Impoverishment.

\section{INTRODUCTION}

A commodity is obviously unaffordable if it cost more than what is in the full or potential budget [1]. The cost of living is the amount of money needed to sustain a certain standard of living by affording basic expenses such as housing, food, taxes and healthcare thus affordability is closely related to cost of living [2].

There are three known approaches of determining affordability of commodity namely catastrophic health expenditure, impoverishment method and the World Health Organisation (WHO)/Health Action International (HAI), all of which have their strengths and weaknesses [3-5].

Catastrophic health expenditure is defined as out-of-pocket spending for health care that exceeds a certain proportion of a household's income with the consequence that those households may suffer the burden of the disease [6]. Out-of-pocket payments are defined as direct payments made by individuals to health care providers at the time of service use [6]. The threshold for health expenditure is arguably $10 \%$ while that of medication expenditure should consume half of the health expenditure [1].

Impoverishment method determine the proportion of populace (sample) that has been made poor as a result of the purchase of a commodity [1,6], while that of WHO/HAI measures affordability of medication by the number of days the least paid government worker will have to work to purchase the medication [2].

Copyright (C) 2020 The Author(s): This is an open-access article distributed under the terms of the Creative Commons Attribution 4.0 International License (CC BY-NC 4.0) which permits unrestricted use, distribution, and reproduction in any medium for non-commercial use provided the original author and source are credited. 
Affordability of antipsychotics is very crucial as it has a way of influencing the standard of living of patients with schizophrenia as well as their quality of life [7, 8]. Antipsychotic medications are indicated among others for the management of Schizophrenia [9, 10]. Schizophrenia is a psychiatric condition characterized with delusions, hallucinations, disorganized speech, disorganized or catatonic behavior and negative symptoms [11].

Schizophrenia is a major cause of disability, with active psychosis ranked as the third-most-disabling condition after quadriplegia, dementia, ahead of paraplegia and blindness. Its risk of disability increases by more than $25 \%$, more work and marital disruption, financial problems, crime, and increased mortality compare to the general population [1214]. The average life expectancy of people with schizophrenia is lower than would be expected for the population as a whole [14].

The Gross Domestic Product (GDP) per capita (which indicates how prosperous a country feels to each of its citizens) in Nigeria was USD2396 in 2018 which is equivalent to $19 \%$ of the world's average meaning that the country is a low-income nation [15]. In addition, 86.9 million (46.7\%) of its populace is recently living in extreme poverty [16], and not forgetting the fact that management of schizophrenia can be lifelong with adverse effects of antipsychotics that may also persist for a long period $[12,13]$. Furthermore, more than $90 \%$ of the populace are involved in out of pocket health care [17], and research on affordability of antipsychotics in Nigeria is rare thus the need for affordability of antipsychotics usage in schizophrenia management is of immense importance

The objective of this study is to determine the levels of impoverishment, catastrophic expenditure and the number of days the least paid government worker will have to work due to out-of-pocket (OOP) payments of antipsychotics in a sample of patients receiving treatment for schizophrenia in Benin City.

\section{METHODS Settings}

This study was conducted in Benin City in the south-south geopolitical zone of Nigeria. The City has a population of over 1.2 million people from the 2006 national population census commission's report and it is made up of four local government areas (LGA), namely Oredo LGA, Ikpoba-Okha LGA, Egor LGA and Ovia north east LGA constituting 12 wards, 10 wards, 10 wards and 13 wards respectively [18].

A two-stage cluster cross sectional sampling was used to select eligible persons. For stage 1, a purposive selection of two different tertiary health institutions, (because they are the only government owned facilities that have the specialized health professionals that can managed people suffering from schizophrenia in the area) one institution from each local government. The hospitals are Federal Neuro- psychiatric hospital (FNPH), a stand-alone specialist facility which has over 250 bed spaces who provides outpatient treatment services on a daily basis excluding weekend, located at Egor LGA; and the University of Benin Teaching hospital (UBTH), a general specialist facility with a capacity of over 800 beds which operates outpatient clinic twice a week, situated at Ovia north east LGA. Each hospital has in their employment consultant psychiatrists, pharmacists, physicians, nurses, psychologists among other health professionals. For stage 2: Two wards were randomly selected from the wards in each LGA of the City then one community pharmacy was randomly chosen from each of the wards selected.

\section{Ethical Consideration}

Ethical approval was gotten from Federal Neuropsychiatric hospital, Benin City research committee with the reference of PH/A.864/vol.vii/12, University of Benin Teaching Hospital was ADM/E22/A/vol.vii/1422 while that from pharmacies, administrative approval was sought from their respective establishments.

\section{Inclusion Criteria}

Recruitment of participants from each of the sites was on voluntary basis after written consent was obtained from them. Where consent was not granted the next person in line was approached to be interviewed. Patients on outpatient basis, not less than 18 years and receiving antipsychotic medication treatment were included in the study. All respondents that took part in the study did out-of-pocket payment for their medications.

\section{Sample size determination and sampling technique}

The sample size was determined using $0.5 \%$ prevalence rate of schizophrenia [19], $1 \%$ precision was employed in the formula $\mathrm{n}=\mathrm{Z}^{2} \mathrm{P}(1-\mathrm{P}) / \mathrm{d}^{2}[20]$, where $\mathrm{n}=$ sample size, $\mathrm{Z}$ statistic for a level of confidence $(95 \%), \mathrm{P}=$ expected prevalence $(0.5 \%), \mathrm{d}=$ precision $(1 \%)$, at least 192 patients with schizophrenia were required. Patients who came to the hospitals' pharmacies and community pharmacies to fill their prescription were systematically randomized using a sampling interval of three. 


\section{Outcome Variables}

The main outcome measures were the poverty headcount ratio, poverty gap index, catastrophic expenditure and the number of days the least paid government worker will have to work due to OOP payments of antipsychotics for those on treatment for schizophrenia.

Impoverishment was defined as a situation where a household income fell below the international poverty line of USD1.9 per day after paying for antipsychotics [21], with the threshold not exceeding 5\% change in impoverishment.

Catastrophic expenditure was defined as OOP payment for antipsychotics exceeding a threshold of 5\% of a household's annual income [22, 23]. WHO and Health Action has defined affordability as OOP payment for antipsychotics not exceeding a threshold of 1 day wage of the least paid government worker should be able to buy a course of treatment 30 days' supply of medicines [24].

The household annual incomes were recorded in Naira (NGN) converted to US Dollars using the exchange rate of USD1 equal to 350NGN [25]. The mean out-of-pocket expenditure of antipsychotics employed in the study was determined and prices of the minimum effective dose of the oral antipsychotics prescribed in the City which were olanzapine $5 \mathrm{mg}$, risperidone $2 \mathrm{mg}$, haloperidol $2 \mathrm{mg}$, trifluoperazine $5 \mathrm{mg}$, chlorpromazine $100 \mathrm{mg}$ were also collected.

\section{Data Collection}

Before the data collection began, 3 research assistants were trained in a 1-day training workshop on how to conduct the interviews and check the information for data completeness. The respondents were approached after payment for their medications while they wait for their medications to be filled in the pharmacy of the study sites. The aim of the study was explained to each respondent. Those who agree to participate sign a consent form and they were interviewed by the investigators using a pretested structured questionnaire.

The questionnaire consisted of two sections, the first section contained questions on sex, age, income per month, marital status, occupation and educational level. The second section recorded the names of the medications and the cost spent on the medications per month, where the therapy is not 30 days medication it was extrapolated to be expenditure of one month therapy by multiplying the cost of a day medication by 30 . Each completed interview was checked promptly for any errors and edited if required. All questionnaires were reviewed at the end of each day for accuracy of the data obtained.

\section{Data Analysis}

This was performed with the $22^{\text {nd }}$ version of the SPSS (SPSS Incorporation; 233 south Walker Drive Chicago IL). Costs of medications used in the study were recorded in mean \pm standard deviation

\section{Impoverishment method}

Poverty headcount ratio $(\mathrm{PH})$ : It was calculated with a formula $\mathrm{PH}=\mathrm{q} / \mathrm{n}$, where $\mathrm{PH}$ is poverty headcount ratio, $\mathrm{n}$ is the number of households with income/expenditure $\mathrm{x}_{1}, \mathrm{x}_{2}, \ldots, \mathrm{x}_{\mathrm{n},}, \mathrm{q}$ is the number of households that have incomes below $\mathrm{z}$, where $\mathrm{z}$ is the amount of poverty line (PL) [26, 27], This assessment was achieved by counting the number of participants that were below the poverty line then dividing it with the sample size of the study. The change in poverty headcount ratio as a result of the medication was determined by subtracting the PH before purchase of medication from that of after the medication expenditure. The percentage of PH relative to that of prepayment was also determined.

$$
\text { Poverty gap Index: Poverty Gap Index (PGI) is PGI }=\frac{1}{N} \sum_{j=1}^{q}\left(\frac{z-y j}{z}\right)^{2} \text { where PGI is Poverty Gap Index, yj is }
$$

the average income for poor households and $\mathrm{z}$ is the amount of poverty line $[26,27]$. The mean of each income group and poverty line were determined. A plot of proportion of the sample ranked (percentage cumulative income frequency) and average monthly income of respondents in each income range in naira was made. This ensures identification of income distribution between two groups of poverty line, one just below the poverty line and the other just after the poverty line. The proportion of sample that were living below the poverty line from the plot was gotten by applying the equation $\mathrm{Y}=\{$ $\left.\left(\mathrm{X}-\mathrm{X}_{1}\right) \mathrm{D}\right\}+\mathrm{C}[1]$, where coordinates $\mathrm{X}_{1}$ is the average monthly income group of respondents just below the PL, $\mathrm{X}$ is the amount of PL, D is the ratio (gradient) which is $\left(\mathrm{Y}_{2}-\mathrm{Y}_{1} / \mathrm{X}_{2}-\mathrm{X}_{1}\right)$ where coordinates of $\left(\mathrm{X}_{1} \mathrm{Y}_{1}\right)$ for points of group below $\mathrm{PL},\left(\mathrm{X}_{2} \mathrm{Y}_{2}\right)$ are coordinates of point of group above PL while $\mathrm{C}$ is proportion of income group just below PL, see Figure1. 


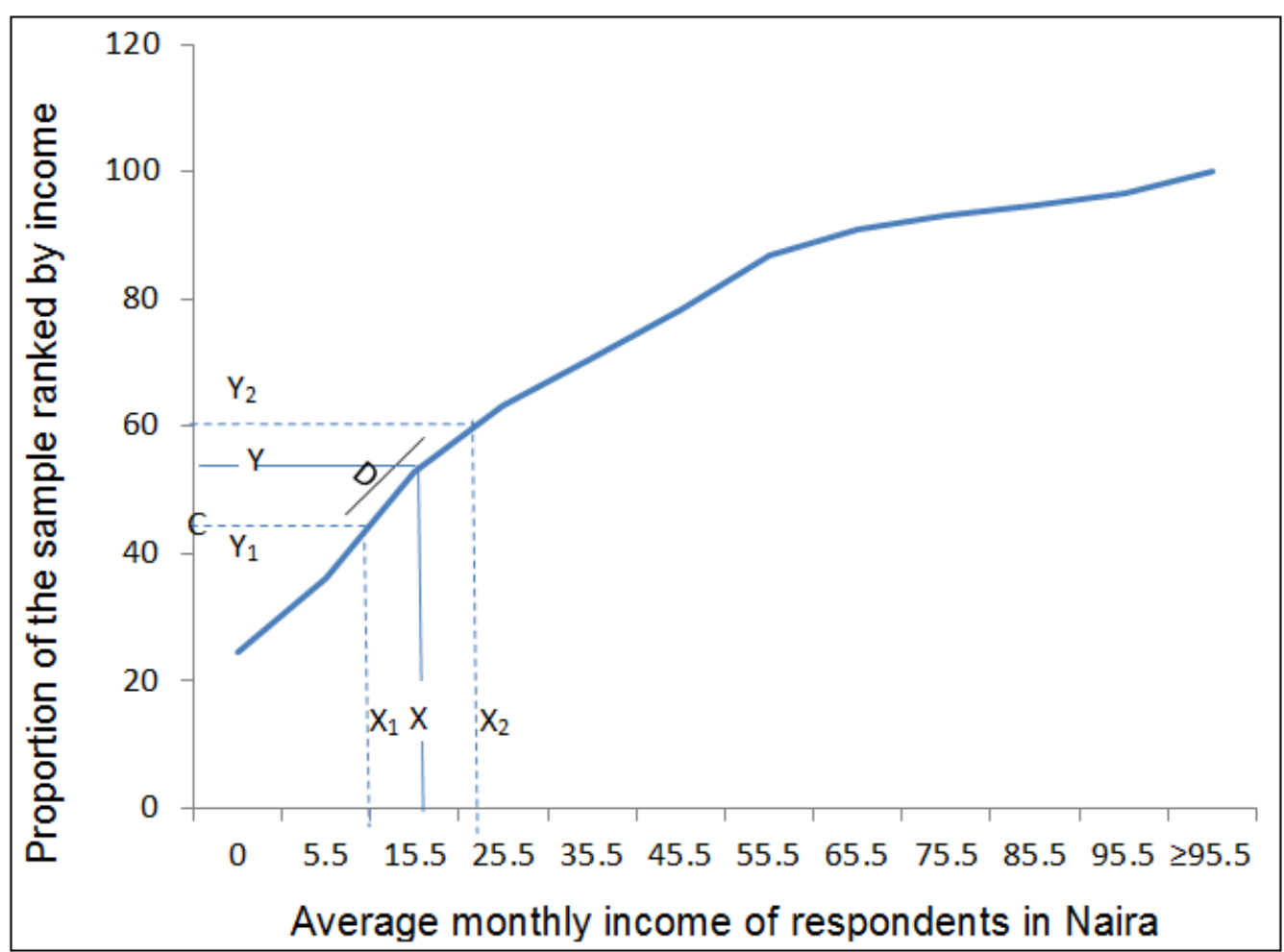

Fig-1: A plot of proportion of the sample ranked by income and average monthly income of respondents in naira

Poverty gap index was determined as the change in the average household amount from that of amount of poverty line before and after the purchase of antipsychotic medication. The percentage of poverty gap index relative to that of prepayment was also determined.

\section{Catastrophic Expenditure}

The percentage of the sample that exceeded 5\% threshold of a medication was determined by estimating the proportion of the population that earns less than 20 times the amount (the minimum effective dose) of the medication.

\section{World Health Organization / Health Action International approach}

The daily wage of the least paid unskilled government worker was calculated by dividing monthly (30 days) pay of the least paid unskilled government worker [minimum wage which is NGN30000 (USD85.71) [28] with 30 days where NGN350 is equivalent to USD1 [25]. The number of days the least paid unskilled government worker will work to pay lowest effective dose an antipsychotic medication was determined by dividing the amount of the medication for 30 days by the amount of daily wage.

\section{RESULTS}

A total of 288 patients with schizophrenia participated in the study which comprised 165 patients, 66 patients and 57 patients from FNPH, UBTH and the community pharmacies respectively. Respondents, $166(58.3 \%)$ were male, $71(24.7 \%)$ not employed, $154(53.5 \%)$ single, 88 (30.6\%) were in age range of 30-39 years, $118(41.0 \%)$ attained secondary level of education while $70(24.3 \%)$ had no personal income, see Table-1. 
Table-1: Baseline characteristics of the socio-demographics of respondents

\begin{tabular}{|c|c|c|}
\hline Demographics & Sub group & Number of respondents (\%) \\
\hline \multirow[t]{2}{*}{ Sex } & Male & $166(58.3)$ \\
\hline & Female & $122(41.7)$ \\
\hline \multirow[t]{6}{*}{ Occupation } & Not employed & $71(24.7)$ \\
\hline & Government employee & $65(22.6)$ \\
\hline & Self employed & $47(16.3)$ \\
\hline & Private employee & $45(15.6)$ \\
\hline & Student & $44(15.3)$ \\
\hline & Retiree & $16(5.5)$ \\
\hline \multirow[t]{4}{*}{ Marital status } & Single & $154(53.5)$ \\
\hline & Married & $80(27.8)$ \\
\hline & Divorced /Separated & $38(13.2)$ \\
\hline & Widow/widower & $16(5.5)$ \\
\hline \multirow[t]{7}{*}{ Age range } & $\leq 19$ years & $12(4.2)$ \\
\hline & 20-29 years & $70(24.3)$ \\
\hline & 30-39 years & $88(30.6)$ \\
\hline & $40-49$ years & $70(24.3)$ \\
\hline & $50-59$ years & $17(5.9)$ \\
\hline & $60-69$ years & $12(4.2)$ \\
\hline & $\geq 70$ years & $19(6.6)$ \\
\hline \multirow[t]{5}{*}{ Educational status } & Primary & $56(19.4)$ \\
\hline & Secondary & $118(41.0)$ \\
\hline & Post-secondary & $69(24.0)$ \\
\hline & Graduate & $26(9.0)$ \\
\hline & Post graduate & $19(6.6)$ \\
\hline \multirow[t]{12}{*}{ Average monthly income } & No personal income & $70(24.3)$ \\
\hline & $1-10$ & $32(11.1)$ \\
\hline & $11-20$ & $48(16.7)$ \\
\hline & $21-30$ & $29(10.1)$ \\
\hline & $31-40$ & $21(7.3)$ \\
\hline & $41-50$ & $26(9.0)$ \\
\hline & $51-60$ & $23(8.0)$ \\
\hline & $61-70$ & $10(3.5)$ \\
\hline & $71-80$ & $6(2.3)$ \\
\hline & $81-89$ & $4(1.53)$ \\
\hline & $91-99$ & $6(2.1)$ \\
\hline & $\leq \mathrm{NGN} 100$ & $13(4.5)$ \\
\hline
\end{tabular}

Prices of the average minimum effective dose of the oral antipsychotics for a month gotten from the settings revealed that olanzapine $5 \mathrm{mg}$, risperidone $2 \mathrm{mg}$, haloperidol $2 \mathrm{mg}$, trifluoperazine $5 \mathrm{mg}$, chlorpromazine $100 \mathrm{mg}$ were NGN1800 (USD5.14), NGN1350 (USD3.86), NGN150 (USD0.43), NGN150 (USD0.43), NGN210 (USD0.60) respectively. The average cost of antipsychotic used by respondents for olanzapine, risperidone, haloperidol, trifluoperazine and chlorpromazine are NGN4230 (USD12.03), NGN 4060 (USD11.6), NGN410 (USD1.17), NGN450 (USD1.29), NGN390 (USD1.11) respectively (Table-2).

Table-2: Payments of the schizophrenics for antipsychotics in Naira $(\mathbf{n}=288)$

\begin{tabular}{|l|l|l|}
\hline Antipsychotics & OOP payments $(\mathbf{M} \pm$ SD) & OOP at lowest effective dose $(\mathbf{M} \pm$ SD) \\
\hline Olanzapine & $4230 \pm 1170$ & $1800 \pm 200$ \\
\hline Risperidone & $4060 \pm 2920$ & $1350 \pm 160$ \\
\hline Haloperidol & $410 \pm 62$ & $150 \pm 50$ \\
\hline Trifluoperazine & $450 \pm 81$ & $150 \pm 50$ \\
\hline Chlorpromazine & $390 \pm 61$ & $210 \pm 50$ \\
\hline
\end{tabular}

$(\mathrm{M} \pm \mathrm{SD})$, Mean \pm Standard Deviation, OOP= Out-of-pocket 
The poverty line (PL) of NGN665 (USD1.9) per day resulting into NGN19950 (USD57) per month using USD1 = NGN350 [25] recorded 156 persons with schizophrenia living below the line before purchase of their medications while those below the poverty line after purchase of olanzapine, risperidone, haloperidol, trifluoperazine or chlorpromazine were $173,167,161,161$ or 159 respondents respectively.

Post-payment average income group just below Poverty line at a proportion of $52.1 \%$ of the sample were NGN11270 (USD32.2), NGN11440 (USD32.69), NGN15090 (USD43.11), NGN15050 (USD43.00), NGN15110 (USD43.11) for olanzapine, risperidone, haloperidol, trifluoperazine, chlorpromazine respectively while that of post payment average income group above poverty line at a proportion of 62.2\% were NGN21270 (USD 60.77), NGN21440 (USD 61.26), NGN25090 (USD 71.69), NGN25050 (USD 71.57), NGN 25110 (USD 71.74) respectively (Table-3).

Table-3: Proportion of the sample ranked by monthly Income In NGN x 1000 of respondents before and after oral antipsychotics medications expenditure $(\mathbf{n}=\mathbf{2 8 8})$.

\begin{tabular}{|l|l|l|l|l|l|l|l|l|}
\hline $\begin{array}{l}\text { Sample } \\
(\%)\end{array}$ & $\begin{array}{l}\text { \% Cum. } \\
\text { sample }\end{array}$ & $\begin{array}{l}\text { Monthly } \\
\text { income }\end{array}$ & $\begin{array}{l}{ }^{\mathrm{a}} \text { Average } \\
\text { monthly income }\end{array}$ & $\begin{array}{l}{ }^{\mathrm{b}} \text { Monthly } \\
\text { Income }\end{array}$ & $\begin{array}{l}{ }^{\mathrm{c}} \text { Monthly } \\
\text { Income }\end{array}$ & $\begin{array}{l}{ }^{\mathrm{d}} \text { Monthly } \\
\text { Income }\end{array}$ & $\begin{array}{l}{ }^{\mathrm{e}} \text { Monthly } \\
\text { Income }\end{array}$ & $\begin{array}{l}\mathrm{f} \text { Monthly } \\
\text { Income }\end{array}$ \\
\hline $70(24.3)$ & 24.3 & $\begin{array}{l}\text { No personal } \\
\text { income }\end{array}$ & 0 & 0 & 0 & 0 & 0 & 0 \\
\hline $\begin{array}{l}32 \\
(11.1)\end{array}$ & 35.4 & $1-10$ & 5.5 & 1.27 & 1.44 & 5.09 & 5.05 & 5.11 \\
\hline $48(16.7)$ & 52.1 & $11-20$ & 15.5 & 11.27 & 11.44 & 15.09 & 15.05 & 15.11 \\
\hline $29(10.1)$ & 62.2 & $21-30$ & 25.5 & 21.27 & 21.44 & 25.09 & 25.05 & 25.11 \\
\hline $21(7.3)$ & 69.5 & $31-40$ & 35.5 & 31.27 & 31.44 & 35.09 & 35.05 & 35.11 \\
\hline $26(9.0)$ & 78.5 & $41-50$ & 45.5 & 41.27 & 41.44 & 45.09 & 45.05 & 45.11 \\
\hline $23(8.0)$ & 86.5 & $51-60$ & 55.5 & 51.27 & 51.44 & 55.09 & 55.05 & 55.11 \\
\hline $10(3.5)$ & 90.0 & $61-70$ & 65.5 & 61.27 & 61.44 & 65.09 & 65.05 & 65.11 \\
\hline $6(2.3)$ & 92.3 & $71-80$ & 75.5 & 71.27 & 71.44 & 75.09 & 75.05 & 75.11 \\
\hline $4(1.5)$ & 93.8 & $81-89$ & 85.5 & 81.27 & 81.44 & 85.09 & 85.05 & 85.11 \\
\hline $6(2.1)$ & 95.5 & $91-99$ & 95.5 & 91.27 & 91.44 & 95.09 & 95.05 & 95.11 \\
\hline $13(4.5)$ & 100 & $\leq$ NGN 100 & $\geq 105.5$ & $\geq 101.27$ & $\geq 101.44$ & $\geq 105.09$ & $\geq 105.05$ & $\geq 105.11$ \\
\hline
\end{tabular}

$\%$ Cum, percentage cumulative frequency. Monthly income a before medication expenditure, ${ }^{\mathrm{b}}$ after Olanzapine expenditure, ${ }^{\mathrm{c}}$ after Risperidone expenditure, ${ }^{\mathrm{d}}$ after Haloperidol expenditure, ${ }^{\mathrm{e}}$ after Trifluoperazine expenditure, ${ }^{\mathrm{f}}$ after Chlorpromazine expenditure.

Using the plot of proportion of the sample ranked by income and average monthly income to determine poverty gap, $56.6 \%$ of the sample was prepayment poverty line proportion (at NGN19950 (USD57) per month) while 60.86\%, $60.74 \%, 57.01 \%, 57.05 \%, 56.98 \%$ were post payment poverty line proportion for olanzapine, risperidone, haloperidol, trifluoperazine, chlorpromazine respectively.

The percentage of patients that were further impoverished using poverty headcount ratios after purchase of olanzapine, risperidone, haloperidol, trifluoperazine and chlorpromazine were $11.1 \%, 7.4 \%, 3.7 \%, 3.7 \%$ and $1.9 \%$ respectively,. The percentage change of Poverty gap after purchase of medications were $7.5 \%, 7.3 \%, 0.7 \%, 0.8 \%, 0.7 \%$ for olanzapine, risperidone, haloperidol, trifluoperazine, chlorpromazine respectively, see Table 4.

Table-4: Impoverishment due to OOP payments for Antipsychotics $(\mathbf{n}=\mathbf{2 8 8})$

\begin{tabular}{|l|l|l|l|l|l|l|}
\hline & & Ola & Ris & Halo & Tri & Chlo \\
\hline & $\begin{array}{l}\text { Pre- } \\
\text { Payment }\end{array}$ & $\begin{array}{l}\text { Post- } \\
\text { Payment }\end{array}$ & $\begin{array}{l}\text { Post- } \\
\text { Payment }\end{array}$ & $\begin{array}{l}\text { Post- } \\
\text { Payment }\end{array}$ & $\begin{array}{l}\text { Post- } \\
\text { Payment }\end{array}$ & $\begin{array}{l}\text { Post- } \\
\text { Payment }\end{array}$ \\
\hline PHC & 0.54 & 0.60 & 0.58 & 0.56 & 0.56 & 0.55 \\
\hline \% PHC change & & 11.1 & 7.4 & 3.7 & 3.7 & 1.9 \\
\hline \% PG & 56.6 & 60.86 & 60.74 & 57.01 & 57.05 & 56.98 \\
\hline \% PG change & & 7.5 & 7.3 & 0.7 & 0.8 & 0.7 \\
\hline
\end{tabular}

$\mathrm{OOP}=$ Out-of-pocket payment, $\mathrm{Ola}=$ Olanzapine, $\mathrm{Ris}=$ Risperidone, $\mathrm{Hal}=$ Haloperidol, Tri $=$ Trifuloperazine, $\mathrm{Chlo}=$ Chlopromazine, $\%$ = percentage, $\mathrm{PHC}=$ Poverty headcount ratio, PGI = Poverty Gap Index.

The proportion of respondents who spend more than $5 \%$ of their income to get their olanzapine, risperidone, haloperidol, trifluoperazine, chlorpromazine were $70 \%, 64 \%, 28 \%, 28 \%, 34 \%$ respectively meanwhile that number of days' wage the least paid government worker will use to purchase the medication were 1.8 day, 1.35 day, 0.15 day,0.15 day, 0.21 day respectively, see Table-5. 
Table-5: Percentage at risk of incurring catastrophic expenditure or number of days' wages used to purchase the minimum effective treatment dose with lowest priced generic of antipsychotics

\begin{tabular}{|l|l|l|}
\hline Antipsychotics & $\begin{array}{l}\text { Catastrophic } \\
\left(\mathrm{X}_{\text {Cat }}\right)^{\mathrm{a}}\end{array}$ & $\begin{array}{l}(\mathrm{WHO} / \\
\mathrm{HAI})^{\mathrm{b}} \\
\text { No of days' wages }\end{array}$ \\
\hline Olanzepine & 70 & 1.8 \\
\hline Risperidone & 64 & 1.35 \\
\hline Haloperidol & 28 & 0.15 \\
\hline Trifluoperazine & 28 & 0.15 \\
\hline Chlorpromazine & 34 & 0.21 \\
\hline
\end{tabular}

$\mathrm{X}_{\mathrm{Cat}}=$ Percentage of the sample at risk of incurring a catastrophic expenditure at a threshold of 5\% of average income. $\mathrm{WHO}=$ World Health Organisation, HAI $=$ Health Action International, ${ }^{\mathrm{a}}$ Catastrophic Method, ${ }^{\mathrm{b}}$ (WHO/HAI) method.

\section{DiSCUSSION}

Demographic distribution of the study revealed that majority of those that were gainfully employed were income earners of not more than NGN20000 (USD57.14) per month. This finding of large number of people with schizophrenia with low income earners was also posited by study where one-fourth of the people living with schizophrenia had no personal income [29]. This proportion of people with schizophrenia may have a negative influence on the affordability of antipsychotics.

The out of pocket payment for the lowest effective dose of olanzapine and risperidone are at least 8 times higher than that of haloperidol, trifluoperazine and chlorpromazine, similar proportion was also seen when the mean out of pocket payment of atypical were compared with that of typical antipsychotics. This implies that one will need to pay as higher as 8 times the cost of typical antipsychotic if such individual is switched to atypical antipsychotic.

The use of atypical antipsychotics such as olanzapine and risperidone have further make more people with schizophrenia more poorer beyond the acceptable limit that was set in the this study while typical antipsychotics namely, haloperidol, trifluoperazine and chlorpromazine were within the limit. The impoverishment rate incurred on patients as a result of being placed on atypical antipsychotics can be unbearable considering the fact that Nigeria is a resource limited country with mirage of economic indicators buttressing the nation's economic stance among community of nations [16, $17,25]$.

Affordability from the catastrophic method perspective revealed that those at incurring risk of unaffordability for atypical antipsychotics was as high as at about twice the risk of the typical antipsychotics suggesting that the affordability of atypical antipsychotics is of concern. This challenge was also put forward from another study done in Washington were the risk of catastrophic expenditure of atypical antipsychotics was $15 \%$ to $20 \%$ [8].

An employee will work for as high as more than a day in order to have enough earnings to procure his or her one month therapy of atypical antipsychotics such as olanzapine, this value is above the bench mark of wage of not more than day to procure medications that will last 30 days for chronic condition [24], while that of typical antipsychotics such as haloperidol, trifluoperazine, chlorpromazine will cost less than half a day's wage. This revelation is in line with another study where it was posited that the number of day's wages that one will work in order to buy only olanzapine or risperidone across some countries in Europe ranged from about 1 to 12 days [8].

Considering the chronic nature of schizophrenia [9, 10], the devastating tendency of this psychiatric condition if not well managed $[12,13]$, and unaffordability of typical antipsychotics, it will be better for respondents visiting these health facilities to be placed on typical antipsychotics but if they must be prescribed atypical antipsychotics due to its superiority in efficacy and tolerability [9, 10], such medications should be subsidized by government or third party payment for majority of the residents. 


\section{Limitation of the study}

We assume linearity and plot the average income of each group at the midpoint that is with the assumption that mean and median are the same, this is quite different in actuality where income distribution within income group will naturally tilt due to the fact that more people in the group will most likely earn income less than the average income. More also, the age range of patients who were less than 18 years old were not collected as inclusion of the set of individuals may give slightly different results.

\section{CONCLUSION}

Patients with schizophrenia in Benin City receiving olanzapine, risperidone, haloperidol, trifluoperazine or chlorpromazine medication to managed their psychiatric condition are being impoverished more by $11.1 \%, 7.4 \%, 3.7 \%$, $3.7 \%$ and $1.9 \%$ respectively, at the risk of catastrophic expenses by $70 \%, 64 \%, 28 \%, 28 \%, 34 \%$ respectively while that of number of days the least paid government worker will have to work to get their drugs were 1.8 day, 1.35 day, 0.15 day, 0.15 day, 0.21 day respectively.

There is need for government, donor agencies and well-meaning individuals to subsidize the cost of antipsychotic medications and/or government should formulate policy that will enroll all people with schizophrenia especially those on the atypical antipsychotic medications on insurance scheme.

\section{Conflict of interest and funding of the study}

Authors declare that there is no conflict of interest before and during the study. This work received no external funding as the authors sole sponsored the research.

\section{ACKNOWLEDGEMENTS}

The authors would like to thank Dr. Isreal Aina, a consultant psychiatrist of UBTH. Also to be appreciated from FNPH are Pharm Ediae IC, pharmacists and intern pharmacists.

\section{REFERENCES}

1. Niens, L. M., Van de Poel, E., Cameron, A., Ewen, M., Laing, R., \& Brouwer W. B. F. (2012). Practical measurement of affordability: an application to medicines. Bulletin of the World Health Organization, 90, $219-227$.

2. Hancock, K. E. (1993). “Can pay?” or economic principles of affordability. Urban Studies, 30,127-145.

3. Stone, M. E. (2006). What is housing affordability? The case for the residual income approach. Housing policy Debate, 17,151-184.

4. Wagstaff, A., \& Van Doorslaer, E. (2003). Catastrophe and impoverishment in paying for health care: with applicationto Vietnam 1993 -1998. Health Economics, 12, 921-934.

5. Flores, G., Krishnakumar, J., O’Donnel, O., \& Van Doorslaer, E. (2008). Coping with health-care costs: implications for the measurement of catastrophic expenditures and poverty. Health Economics, 17, 1393-1412.

6. Ekman, B. (2007). Catastrophic health payments and health insurance: some counterintuitive evidence from one low income country. Health Policy, 83,304-313.

7. Wu, M., Kennedy, J., Cohen, L. J., \& Wang, C. (2009). Coverage antipsychotics among medicare drug plans in the state of Washington: changes between 2007 and 2008. Primary care companion to the Journal of clinical psychiatry, 11(6),316.

8. Zaprutko, T., Kopciuch, D., Kus, K., Merks, P., Nowicka, M., \& Augustyniak, L. (2017). Affordability of Medicines in the European Union. Plos ONE, 12(2), e0172753.

9. Enato, E. F. O., \& Aina, I. (2010). Pharmaceutical care in Psychiatric. In: Oparah A.C. Essentials of pharmaceutical care. Nigeria: All Deals investment company limited, 353-393.

10. Katzung, B. G. (2011). Basic and clinical pharmacology $11^{\text {th }}$ Edition. Singapore: the MCGraw Hill companies, 54880 .

11. Diagnostic and Statistical Manual of Mental Disorders DSM-V. 5th ed. Arlington, Via: American Psychiatric Association 2013. Available at http://www.psychiatryonline.com. [Accessed: $23^{\text {rd }}$ February 2019].

12. Palmer, B. A., Pankratz, V. S., \& Bostwick, J. M. (2005). The lifetime risk of suicide in schizophrenia: a reexamination. Archives of General Psychiatry, 62(3),247-253.

13. Suleiman, T. G., Ohaeri, J. U., Lawal, R. A., Haruna, A. Y., \& Orija, O. B. (1997) Financial cost of treating outpatients with schizophrenia in Nigeria. Bristish Journal Psychiatry, 171,364-368.

14. Sharpe, M. C., \& Lawrie, S. M. Medical psychiatry. (2010). In: Nick, R. C., Brian, R. W., \& Stuart, H. R. (eds) (2010). Davidson's Principles and practice of medicine $21^{\text {st }}$ Edition, 242-243.

15. Nigeria GDP. (2019) Data Chart Calendar Forecast News. Available at https://tradingeconomics.com. [Accessed: $23^{\text {rd }}$ July 2019] 
16. Kazeem, Y. (2019). Nigeria's has the highest rate of extreme poverty globally-Quartz. Available at https://qz.com. [Accessed: $23^{\text {rd }}$ February 2019]

17. Olukoya, O. (2017). NHIS Has Covered Less Than 5\% of Nigeria's Population. Nigeria Tribune. 10, August 2017, Available at https://www.tribuneng.com. [Accessed: $25^{\text {th }}$ February 2019].

18. Report of Nigeria's National Population Commission on the 2006 Census-JStor. Available at https://www.jstor.org. [Accessed: 3rdJuly 2019]

19. Esan, O. B., Ojagbemi, A., \& Gureje, O. (2012). Epidemiology of schizophreania- An update with a focus on developing countries. International Review of Psychiatric, 24(5), 387-392.

20. Pourhoseingholi, M. A., Vahedi, M., \& Rahimzadeh, M. (2013). Sample size calculation in medical studies. Gastroenterol Hepatol Bed Bench, 6(1),14-17

21. Bank, W. (2017). Country poverty brief, Myanmar Washington, D.C: World Bank. Available at https://www.worldbank.org. [Accessed: 19 ${ }^{\text {th }}$ July 2019]

22. Mclntyre, D., Thiede, M., Dahlgren, G., \& Whitehead, M. (2006). What are the economic consequences for household of illness and of paying for health care in low- and middle-income country contexts? Social Science and Medicine, 62,858-865.

23. Xu, K. (2003). Household Catastrophic health expenditure: A multi-country analysis. The lancet, 362,111-117

24. Nina, S., Alessandra, F., Ganna, B., \& Panos, K. (2014). Availability and Affordability of medicines and assessment of quality systems for prescription of medicines in the republic of Moldova. Republic of Moldova Health Policy Paper Series, 6, 1-9.

25. Nigerian Naira Exchange rate- Central Bank of Nigeria Exchange rate. Available at https://www.cbn.gov.ng. [Accessed: 20 ${ }^{\text {th }}$ February, 2029]

26. Madden, D. (2000). Poverty in Ireland, 1987-1994: A Stochastic Dominance Approach. The Economic and Social Review, 3(31), 187-214

27. Myint, A. N. M., Liabsuetrakul, T., Htay, T. T., Wai, M. M., Sundby, J., \& Espen, B. (2018). Impoverishment and catastrophic expenditures due to out-of-pocket payments for antenatal and delivery care in Yangon Region, Myanmar: a cross-sectional study. British Medical Journal, 8, e022380.

28. Buhari Orders Payment of Minimum Wage But Says No Increase For Workers Earning N30,000 and Above. Available at https://www.saharareporter.com. [Accessed: 20 ${ }^{\text {th }}$ July 2019]

29. Polsky, D., Doshi, J. A., Bauer, M. S., \& Glick, H. A. (2006). Clinical trial-based cost-effectiveness analyses of antipsychotic use. American Journal of Psychiatry, 163(12), 2047-2056. 